\title{
On Books
}

\section{Punished by Misunderstanding: A Critical Evaluation of Kohn's Punished by Rewards and Its Implications for Behavioral Interventions with Children}

\author{
David Reitman \\ Louisiana State University
}

\begin{abstract}
Despite the growth of behavior analysis over the past 30 years, misunderstandings of behavioral theory and practice may threaten its continued growth and application. Alfie Kohn's Punished by Rewards: The Trouble with Gold Stars, Incentive Plans, A's, Praise, and Other Bribes (1993) offers a view of behaviorism that, if accepted uncritically, could hinder efforts to disseminate behavioral interventions, particularly those involving children. A comprehensive review of Punished by $R e$ wards revealed the following assumptions: (a) Behavior analysis is exclusively derived from animal research; (b) behavior analysts characterize children as passive agents to be manipulated; (c) behavior analysis is a behavior control technology; (d) behavior analysts are uninterested in and ignorant of the causes of behavior; and (e) behavior analysts are unconcerned about the protection and welfare of children. For each class of assumptions, critique and commentary are offered. Empirical and philosophical aspects of Kohn's arguments are scrutinized, and the implications of continued misunderstandings for the future of behavior analysis and the need for more accurate dissemination of contemporary applied behavioral research are also discussed. Despite Kohn's apparent biases against behaviorism, it is concluded that a better informed public would find much to like about contemporary behavior analysis.
\end{abstract}

Key words: behaviorism, behavior therapy, critical review, children, intrinsic motivation

Is image everything? If so, behavior analysis may have a problem. Behavior analysis, and more generally, behaviorism, have been misrepresented in both the academic (Todd \& Morris, 1983; 1992) and popular press (Eisenberger

Kohn, A. (1993). Punished by rewards: The trouble with gold stars, incentive plans, $A$ 's. praise, and other bribes. New York: Houghton Mifflin.

An earlier version of this article was presented in R. Gallagher (Chair), Externalizing behavior disorders in youth: Where we stand and where we should be heading, at the 30th annual meeting of the Association for the Advancement of Behavior Therapy, New York, November 1996. I thank Stephen R. Flora, Robert P. Hawkins, and Joseph C. Witt for their comments on an earlier draft of this paper and acknowledge research assistance from Steven Hupp, Paula Rhode, Rebecca Currier, and Jordan Abshire.

Correspondence concerning this article should be addressed to David Reitman, Department of Psychology, Louisiana State University, $236 \mathrm{Au}-$ dubon Hall, Baton Rouge, Louisiana 70803 (Email: dreitma@unix1.sncc.lsu.edu).
\& Cameron, 1996). Even those more familiar with applied behavioral interventions may oppose the approach on philosophical grounds (Axelrod, 1996). For example, Woolfolk, Woolfolk, and Wilson (1977) found that preservice teachers who watched a videotape of a teacher using behavior modification techniques rated the procedures more positively when the intervention was described as "humanistic education" than when it was described as "behavior modification." Among undergraduates surveyed, $79 \%$ disagreed with the statement, "It is appropriate to use behavior modification with normal children" (Turkat, Harris, \& Forehand, 1979). In addition, Favell's (1977) introduction to a volume on behavior modification notes that behavioral interventions have been unfairly associated with psychosurgery and a reliance on aversive methods. After 30 years, 
behaviorism and behavior analysis seem to be in need of a makeover.

\section{Purpose}

The intent of this paper is to evaluate the basic assumptions and claims made in Kohn's Punished by Rewards: The Trouble with Gold Stars, Incentive Plans, A's, Praise, and Other Bribes (1993). Where distortions or misrepresentations of behavior analysis or behaviorism are revealed, clarification or contrary evidence will be presented. Points of convergence between Kohn's views and those of contemporary behavior analysts will also be highlighted. As in Maurice's (1996) emotional address to the annual convention of the Association for Behavior Analysis (ABA), it is argued that the misrepresentations and philosophical arguments presented against behaviorism in Kohn's text could add to existing negative perceptions of behavioral interventions and thus prevent many children from receiving the care best suited to promoting their healthy growth and development.

Punished by Rewards should be of interest to behavior analysts and others who are responsible for the protection and welfare of children for several reasons. First, the text brings together a large body of research and philosophy that challenges some of behaviorism's and, according to Kohn, the lay public's core assumptions about education and parenting. Second, Kohn reproduces a host of controversial assertions that echo those frequently encountered by behaviorists in applied and academic settings. Third, in contrast to more academically targeted critiques (e.g., Deci \& Ryan, 1985), Punished by Rewards was written for lay audiences and has been widely read (over 63,000 copies sold to date).

\section{Other Reviews}

Previous reviews of Punished by Rewards have been mixed. Organizational psychologist Montemayor (1995) reviewed the book for Personnel Psy- chology and concluded that Kohn's criticisms were not relevant to applications of behavioral principles in vocational settings. Clifford (1996) reviewed the text for Contemporary Psychology and, although generally supportive of Kohn's arguments, questioned the feasibility of completely abandoning contingent reward in the classroom. Neither author seriously challenged Kohn's broad claims or the body of research alleged to support those claims. Moreover, neither review examined the philosophical basis of Kohn's arguments. Interestingly, no substantive review of Punished by Rewards has yet appeared in behaviorally oriented journals, despite its apparent relevance to behavior analysts.

As both Montemayor (1995) and Clifford (1996) recognize, Kohn finds empirical support for his views in laboratory research employing both adults (often college students) and children as participants (e.g., Deci \& Ryan, 1985; Lepper \& Greene, 1975, 1978). The purpose of the present paper is not to critique earlier laboratory work on intrinsic motivation (for critical reviews, see Dickinson, 1989; Flora, 1990), but to evaluate Kohn's portrayal of behavior analysis and contrast it with a survey of applied research with children and adolescents. Such an analysis is especially critical given Kohn and others' concerns about the potentially harmful impact of systematic applications of contingent reward in our homes and schools.

\section{Punished by Misunderstanding: Kohn's View of Behavior Analysis}

The central thesis of Kohn's book is that contingent reward is undesirable on both practical and philosophical grounds. Divided into three parts, Part 1 contains Kohn's philosophical and empirical arguments against behaviorism. Next, Kohn exposes what he terms the "core philosophy" of Skinnerian behaviorism: "Do this and you'll get that." Kohn then argues against the allegedly widespread appli- 
cation of operantly influenced interventions in school, home, and vocational settings.' In contrast to popular and professional notions about the effectiveness and desirability of rewarding children's behavior, Kohn charges that contingent rewards reduce creativity and risk taking, diminish performance quality, and cause children and adults to lose intrinsic interest in tasks for which they are rewarded (for a detailed response to these criticisms, see Eisenberger \& Cameron, 1996).

In Part 2, Kohn describes the allegedly harmful impact of rewards in school and home settings. Drawing selectively from both published research and anecdotal accounts, Kohn paints a bleak picture of how rewards fail to produce the favorable outcomes often ascribed to them. For example, Kohn's critique of competitive grading policies is directed at administrators, teachers, and an educational system that he perceives as imbued with a behaviorist philosophy. Kohn is especially critical of what he considers to be the widespread thoughtless introduction of arbitrary rewards for performance in home and classroom settings.

Later in Part 2, Kohn presents the work of Lepper and Greene (1975) and Deci and Ryan (1985), who, among others, promote the view that both punishing and rewarding children, although sometimes effective in generating shortterm compliance, do little to foster long-term growth and development. Drawing from this research base, Kohn charges that contingent reward ultimately yields children, adolescents, and adults who lack intrinsic interest in learning or work and whose behavior is controlled nearly exclusively by extrinsic motivators such as money and praise. Unfortunately, long-term (e.g., longer than 1 month) controlled studies of the impact of contingent reward on

\footnotetext{
'Kohn's comments on behavioral interventions in the workplace are not considered here, but see Montemayor (1995) for relevant criticisms of Kohn's views as they apply to vocational settings.
}

either achievement or task interest are rare, and the few existing studies appear to be inconsistent (see Kohn, 1993, note 13, p. 299). No evidence of detrimental long-term effects of the sort necessary to justify Kohn's concerns is readily available. However, neither is there compelling evidence to dismiss Kohn's claims. Specifically, all known studies of the alleged detrimental effects of reward involve only brief exposure to rewards, so conclusions about their potential harmful effects await studies in which the participants are exposed to contingent reward for much longer periods (e.g., weeks or months) (Bernstein, 1990).

In Part 3, Kohn describes alternatives to methods based on what he terms the "carrot and stick" approach. As noted by Clifford (1996), these ideas are less well developed than Kohn's exhaustive criticisms of behaviorism. Kohn's introduction of "the three Cs"-collaborative learning environments, modified course content, and increased student choice-is followed by the suggestion that teachers adopt this approach and abandon the use of contingent reward to motivate children. Unfortunately, however attractive Kohn's recommendations may be, little empirical evidence suggests that his solutions will yield better educational outcomes than existing practices (Clifford, 1996). For example, Slavin's (1991) critical examination of the cooperative learning literature led to the conclusion that achievement gains were produced only when both group and individual rewards were programmed. Commenting on the somewhat paradoxical popularity of cooperative learning, Slavin noted,

The cooperative learning movement has created an interesting phenomenon, in which humanistic educators and psychologists are championing classroom methods that could be described completely in behavioral language. . . . However, the attraction of cooperative learning for many humanistic educators probably lies not so much in accelerating student achievement as in the consistently found positive effects on such variables as race relations, attitudes toward mainstreamed classmates, self-esteem, and other non-academic 
outcomes. . . In contrast to achievement effects, these important outcomes do not appear to depend on the use of group rewards for individual learning. (p. 113, italics added)

Thus, although the promotion of collaboration, choice, and changes in lesson content may enhance some aspects of children's educational experiences, it does not follow from the existing research that we ought to abandon the use of reward in the classroom. Properly employed, extrinsic rewards can be important and useful motivational tools (Travers, Elliot, \& Kratochwill, 1993). At the same time, the delivery of arbitrary rewards for good performance does not, by itself, constitute a well-conceived educational plan. As will be described later, contemporary behavioral approaches to teaching concentrate more on instructional design than on arbitrary schemes for the delivery of extrinsic rewards.

\section{An Alternative Perspective on Behavior Analysis: A Reply to Kohn}

Far from being comprehensive, Kohn's selected literature review highlights failures while ignoring the many successes associated with behavioral interventions. In particular, Kohn seems to be oblivious to behavioral interventions that do not hold compliance as an explicit goal (see Miltenberger, 1997, for many examples of the successful application of behavioral principles that do not involve compliance training) and is largely unaware of the behavioral literature debating the ethics of reward and punishment (e.g., Van Houten et al., 1988; Wolpe, 1978). On the whole, Punished by Rewards presents a rather unattractive behavioral straw man that vastly underrates the utility of behavioral interventions and disingenuously portrays the motives of parents, teachers, and behavior modifiers.

As will later be shown, there are many points of correspondence between Kohn's views and those of applied behaviorists. Still, the misrepresentations of contemporary behavior- ism present in Punished by Rewards may cause considerable concern among school administrators, teachers, parents, and others who, up until now, have been receptive to behavioral interventions. In citing Charles Darwin-"Great is the power of steady misrepresentation; but the history of science shows that fortunately this power does not long endure"-Todd and Morris (1992, p. 1450) hoped that misrepresentations of behaviorism would ultimately give way to more even-handed accounts. Punished by Rewards is formidable evidence that prejudiced accounts have yet to give way to fair representation. Consequently, a more complete examination of the most consistently voiced misunderstandings and misrepresentations reflected in Kohn's text may be necessary to assist behavior analysts in responding to the concerns about behaviorism raised in Punished by Rewards and to foster more accurate representation of behavior analysis in the future.

Using direct quotations from Punished by Rewards, the following classes of misrepresentation or misunderstanding were identified: (a) Behavior analysis is exclusively derived from animal research; (b) behavior analysts characterize children as passive agents to be manipulated; (c) behavior analysis is a behavior control technology; (d) behavior analysts are uninterested in and ignorant of the causes of behavior; and (e) behavior analysts are unconcerned about the protection and welfare of children. Following each assumption and representative quotations from the text, critique and commentary are offered.

Behavior analysis, and more broadly behaviorism, is based primarily upon work that has been conducted with animals, in particular, rats and pigeons.

As behaviorists cheerfully admit, theories about rewards and various practical programs of behavior modification are mostly based on work with rats and pigeons. ... Yet it is not an accident that the theory behind "Do this and you'll 
get that" derives from work with other species, or that behavior management is frequently described in words better suited to animals. (p. 24)

Although largely true in 1960 , it is no longer the case that the empirical base of behavior analysis derives exclusively from animal research. Over the past 30 years, basic research and innovation in therapy have extended the principles of applied behavior analysis to human participants. Basic research examining phenomena such as stimulus equivalence and instructional control has been conducted almost exclusively with humans (e.g., Hayes \& Hayes, 1992; Sidman, 1994). Since the early 1980 s, there has been a behavioral journal dedicated to the examination of human verbal processes (The Analysis of Verbal Behavior), and the Journal of the Experimental Analysis of Behavior, a premier behavioral experimental journal, has published an ever-increasing number of articles involving humans (Nevin, 1982). Similarly, the Journal of Applied Behavior Analysis and Behavior Modification have published behavioral research involving only human participants since their inception in the late 1960s and mid1970 s, respectively.

Although Kohn's claim that behavior analysis is based primarily on animal research is obviously false, so too is the implication that basic research with animals is irrelevant to humans. For example, early discoveries in genetics derived from work with plants. Nevertheless, the mechanisms of gene transmission across the species, including humans, have been shown to have wide generality. Further, basic research on the effects of drugs and medical procedures is usually first conducted with animals, and these trials often serve as vital guides for human applications. Thus behaviorism's connection to animal research in no way limits its potential utility in guiding human affairs.

Behavior analysis characterizes the child as a passive agent to be manipulated.
The behaviorist's conception of human beings as passive beings whose behavior must be elicited by external motivation in the form of incentives is, by any measure, outdated. (p. 25)

Behavior management systems turn teachers into technicians and students into "objects to be manipulated, shaped, or molded"-passive agents of our actions rather than contributing members of the educational process. (pp. 154155)

It is all of a piece, ... the view of children (and ultimately all organisms) as inert objects that must be motivated to learn from the outside with the use of reinforcements and threats. (pp. 213214)

The behavior analyst's preference for a model of human behavior that places causes outside the individual and eliminates human agency has certainly been one of the least appealing aspects of behavioral accounts of human behavior (Skinner, 1953). Even some early behaviorists, now cognitive behaviorists, have found the hard determinist position to be untenable (e.g., Mahoney, 1995). Nevertheless, although unpopular with many, this pragmatic model of human behavior is solution focused and empirically grounded and has made significant advances in the treatment of children's behavior problems possible on wide scale in a very short time (Miltenberger, 1997). Moreover, the empirical foundation of behavior analysis helps to ensure that effective treatments are selected and refined while ineffective or impractical interventions are abandoned.

Despite behaviorism's unpopular position on human agency, to argue that behavior analysts regard children as "objects to be manipulated" is gratuitous. A more accurate contemporary view is exemplified by G. Patterson (1982), who views the behavior of parent and child as intricately related. In Patterson's model, parent and child are considered to be individual participants in an interlocking set of social contingencies. Similarly, Gewirtz (1978) has commented that "just as the care giver can condition the child's behavior by providing reinforcing consequences, so can the child's behavior mediate rein- 
forcing stimuli that condition the responses of the care giver" (p. 113). Thus, although behaviorists eschew internal causal agents in their explanations of human behavior, their accounts typically go beyond assumptions of unidirectional (e.g., parent or teacher to child) causation to encompass more complex relations.

Behavioral methods are widely used in educational settings for behavior control, and this constitutes the only reliable effect: generating obedience.

What rewards and punishments do is induce compliance, and this they do very well indeed. If your objective is to get people to obey an order, to show up on time and do what they're told, then bribing or threatening them may be sensible strategies. (p. 41)

And, with respect to working with children diagnosed with developmental disabilities, Kohn states,

Behavioral management in practice typically meant obedience rather than helping "children to become self-directed and to assume responsibility for their behavior." In fact, one study showed that teachers of retarded children were so intent on reinforcing certain (adult specified) behaviors that as a rule they tended to ignore the children's choices and expressions of preference. ... Students' spontaneous behaviors, which may be meaningful to them and important to their overall development, are automatically viewed as interfering with the behavioral goals that have been established by adults. (pp. 154-155)

Although few would deny that behavioral programs are frequently used for behavior management or to gain compliance (probably too exclusively so in some settings), a wealth of research documents behavioral interventions that focus upon skill acquisition and instruction (Johnson \& Layng, 1992). A short list of other applications of behavioral principles that go beyond gaining compliance would include efforts to teach self-management skills (Brigham, 1989), promote self-care (Scotti, McMorrow, \& Trawitzski, 1993), improve abduction prevention procedures (Carroll-Rowan \& Miltenberger, 1994), and enhance sports performances (Martin \& Hrycaiko, 1983). Nevertheless, throughout Punished by Rewards the reader is subjected to por- trayals of teachers, parents, and behavior modifiers acting against the longterm best interests of children; this seems to be a poorly informed, biased depiction (see Goodall, 1972, for an alternative, more positive portrayal).

Despite Kohn's hyperbole, it remains worth considering whether or not applied efforts have reflected sufficient appreciation of the values that underlie clinical and educational activities. Thus Kohn's concern that behavioral interventions may have deleterious effects, whether based on punishment or reinforcement, warrants serious consideration. Indeed, similar concerns have been raised before by those within the behavior-analytic community (see Balsam \& Bondy, 1983; O'Leary, 1972; Winett \& Winkler, 1972):

For many years, the focus on having mildly disruptive or inattentive children pay attention went unchallenged. A large number of investigations have since shown that improving attentiveness among students in the classroom does not improve academic performance. Perhaps proponents of behavior modification have been too apt to embrace goals selected by others-having "well-behaved and quiet children"-while neglecting major goals of education such as improved academic performance. (Kazdin, 1989, p. 319)

In conclusion, it can scarcely be said that applied behaviorists have failed to consider the ethics of their professional activities. On the contrary, behavior therapists have been on the forefront of patient advocacy and efforts to enhance the lives of the less fortunate.

In another sort of misrepresentation, Punished by Rewards frequently portrays unfair evaluation and grading practices and the ruthless competition they may engender as inevitable consequences of Skinnerian behaviorism. However, a recent journal volume dedicated to the teaching of behavior analysis focuses on procedures to enhance interest or teach concepts more precisely, rather than grading procedures. In fact, only 2 of 20 articles explicitly mention grading (see The Behavior Analyst, 1995, Vol. 18). Finally, Michael's (1991) behavioral analysis of intra- 
group contingencies and college grading suggested that only a subset of grading practices (e.g., norm-referenced, "grading on the curve") created undesirable, "viciously competitive" learning environments. Like Kohn, Michael (1991) is critical of competitive grading practices.

Kohn's depiction of behaviorism as being responsible for our current educational malaise is all the more ironic, given Skinner's disappointment that he failed to significantly influence educational practices in the United States (Skinner, 1984). One of the most unfortunate aspects of Kohn's portrayal of applied behaviorism in educational settings is that the instructional techniques (e.g., programmed instruction, direct instruction, and precision teaching) and technical innovations (e.g., teaching machines and programmed texts) developed by behavior modifiers appear to be based upon principles that Kohn describes as wholly desirable: mastery-based learning achieved with nonevaluative, rapid feedback (Buskist, Cush, \& DeGrandpre, 1991; Kinder \& Carnine, 1991; Skinner, 1968; Vargas \& Vargas, 1991; West \& Young, 1992). Regrettably, Kohn seems to be unaware of the many educational innovations that have been developed from within the behavior-analytic perspective.

Behavior analysis consists largely of interventions that focus upon manipulating behavior via rewards and punishments without concern for causes.

Reward and punishment are deficient partly because they attempt to control behavior without regard to its cause. Different schools of thought will tend to identify different reasons for behavior, emphasizing for example, the child's need for attention, the example that has been set for him (he may be aggressive with his friend because his parent is aggressive with him), the network of relationships in the family or the classroom, and so on. Theories aside, different circumstances will lend different meanings to the same sort of behavior. (p. 237)

Ironically, Kohn's analysis of this hypothetical child's behavior would be quite familiar to behavior analysts. Although Punished by Rewards consis- tently portrays applied behaviorism as a "carrot and stick" psychology that is uninterested in "causes," such a characterization fails to recognize functional analysis, one of the most rapidly growing areas of applied behavior analysis. Functional analysis is defined as the experimental analysis of behavioral function, or stated differently, its causes. Although the experimental analysis of function is a more recent phenomenon in the clinical literature (Vollmer \& Northup, 1996), conceptual functional analysis is by no means new to applied behaviorism. Ferster (1965), one of the first behaviorists to extend operant conditioning principles to human participants in natural settings, put it this way:

To classify behavior, we must take into account both static and dynamic factors or, in other terms, a topographic and functional analysis. A static or topographical analysis essentially describes what occurred. ... Such a record may be as objective and as reproducible as any other datum in biology. It lacks however, the functional or dynamic relation of behavior to a controlling environment. (p. 9)

More recently, Carr (1993) made this somewhat surprising (even to some behaviorists) commentary:

As operant psychologists, we are concerned first and foremost, with the functions of behavior, or in lay terms, with purpose. ... True behavior analysts have, paradoxically, very little interest in behavior. Thus, knowing that a young boy diagnosed as autistic exhibits self-injury is, by itself, not very interesting. What is interesting is why the self-injury occurs (i.e., of what variables is it a function). (p. 48)

State-of-the-art interventions with children diagnosed with developmental disabilities, in contrast to the practices described by Kohn, typically necessitate functional analyses designed to experimentally evaluate the relation of the child's behavior to its consequences. As Kohn implies, a child's misbehavior may indeed have a communicative function. Behavior analysis can help to determine whether target behaviors function to produce attention, escape, tangible reinforcers, or appear to serve some other function (Vollmer \& Northup, 1996). Moreover, 
functional analysis can often lead to interventions that do not involve the creation and manipulation of arbitrary behavior-reinforcer relations but that actually alter the context in which those behaviors occur (e.g., they involve changes in the content of instruction or changes in scheduling family activities), much as Kohn recommends (Huynen, Lutzker, Bigelow, Touchette, \& Campbell, 1996; A. Schwartz \& Goldiamond, 1975). Thus, a behavioral intervention that attends to causes is good behavior analysis.

Behavior analysts are unconcerned about the protection and welfare of children.

One way or another, millions of children learn to shut up and do what they are told. This lesson is typically enforced by classroom management programs .... [that] amount to bribes and threats to enforce rules that the teacher alone devises. Children are rewarded for mindless obedience; the names of students who fail to obey are written on the blackboard for all to see; questions or objections are dismissed as irrelevant. All problems in the classroom are attributed to the students, and punishments imposed on them are said to result from their "choices." (p. 165)

When a teacher complains that students are "off-task"- a favorite bit of educational jargon-the behaviorist will leap to the rescue with a program to get them back "on" again. The more reasonable response to this complaint is to ask, "What's the task?"' (p. 218)

They [mothers, teachers] may need time to give up the quick fixes of pop behaviorism. (p. 234)

A seemingly common assumption of many persons outside behavior analysis is to assume that behavior analysts are quick to impose restrictions on the freedom of others. Characterizations of behavioral interventions as "quick fixes," controlling or restrictive of choice, and lacking concern for the ethics of exercising control betray the considerable attention that has been directed toward the use of aversive treatments, the ethics of control in general, and behavioral research evaluating the potential negative side effects of both punishment and reward. For two decades, behavior analysts have been at the forefront of dialogues on the ethics of control and the use of both punishment and reward (Azrin, Stuart, Risley, \& Stolz, 1977; Balsam \& Bondy, 1983; Favell \& McGimsey, 1993; Kazdin, 1989; Repp \& Singh, 1990; Vasta, 1981). In addition, treatment acceptability studies devised by behavioral researchers address ethical concerns by virtue of informing clinicians of client preference (Elliot, 1988).

Despite Kohn's claims that behavior management programs inherently involve "bribes and threats to enforce rules that the teacher alone devises" (p. 165), most persons capable of participating in designing their own treatment plans actively contribute to them (Davidson \& Stuart, 1975; Wolpe, 1978). Sophisticated interventionists understand the value of gaining the child's cooperation through reasoned discussion, and the child's contribution to treatment is considered vital to an intervention's success. For example, child behavior therapists explicitly recommend including parents and their adolescents or children in the decisionmaking process when devising behavior management plans (Kelley \& Stokes, 1982).

Also disconcerting is Kohn's suggestion that fostering problem solving between children and those responsible for their welfare is somehow alien to applied behavioral treatments for children. In fact, behavioral contracting, a procedure for facilitating problem solving that was developed by behavior therapists, has long been considered a valuable tool for fostering improved family relationships (Kelley \& Stokes, 1982; Stuart, 1971). Finally, although Kohn provides no empirical justification for his recommendation that parents and teachers utilize a "problemsolving approach" in their interactions with children (see Part 3), numerous references to applications of problem solving can be found-in the writings of behaviorists (see Kanfer \& Busemeyer, 1982; Nezu \& Nezu, 1989; Skinner, 1966)!

Kohn's commentary on the use of reward in the home environment is yet another instance in which his unfamil- 
iarity with contemporary behaviorism and its concern for the welfare of persons is evident. Specifically, Kohn suggests,

Limits and structures can be endorsed most readily when the purpose is defensible (for example protecting a child from injuring himself), their restrictiveness is minimized (for example, preventing access to certain cabinets rather than forcing a toddler to stay in one small space), and the child has contributed to the arrangement to the fullest possible extent (for example, in helping come up with a plan for getting homework done). ... Still, it seems reasonable to propose that parents and teachers try to use the least intrusive or coercive strategy necessary to achieve a reasonable end. (p. 230)

Of course, Kohn's statements are clearly consistent with positions taken by behavior analysts over the past 20 years. Explicit guidelines for the use of behavioral interventions were published in The Behavior Analyst (Van Houten et al., 1988) nearly 10 years ago in order to facilitate "both the ethical and appropriate application of behavioral treatment" (p. 111). Ten years prior, similar guidelines were published in Behavior Therapy (Azrin et al., 1977). These guidelines continue to facilitate the selection of the least restrictive treatment alternatives while maximizing client choice, comfort, and treatment effectiveness.

\section{The Empirical Basis for Kohn's Claims}

The core of Kohn's argument against behaviorism rests upon a research base that purports to demonstrate reductions in a person's task engagement and his or her self-reported ratings of interest (i.e., intrinsic interest) in those tasks for which he or she is contingently rewarded (e.g., Deci \& Ryan, 1985; Lepper \& Greene, 1975). Yet despite Kohn's broad claims, a recent metaanalysis of nearly 100 intrinsic motivation studies suggests that the loss of intrinsic motivation appears only under a highly circumscribed set of circumstances (Cameron \& Pierce, 1994). Specifically, tangible rewards (e.g., food, tokens) appear to undermine intrinsic motivation when they are prom- ised (or expected) and when they are delivered contingent upon task engagement rather than specifying the quality of the performance required for reward. Praise, by contrast, usually appears to be interest and activity enhancing or, at worst, neutral, whenever it is introduced. Thus, we need to ask ourselves how commonly promised, tangible, performance-independent rewards are delivered in the real world in order to assess the implications of these findings. Do parents and teachers frequently promise and deliver rewards without attention to performance quality? Data on this point would be of interest, but they are not provided by Kohn.

Empirical data from other sources suggest that there would be little to be concerned about even if tangible, expected, quality-independent reinforcement were common. For example, single-case investigations of the undermining effect have shown that the effect is transient and probably does not persist (e.g., Dickinson, 1989; Vasta \& Stirpe, 1979). Not surprisingly, Kohn dismisses such single-case investigations (i.e., behavior-analytic research) of intrinsic motivation and creativity largely because many of these studies utilize only a "handful of subjects" and "no control group." Thus Kohn appears to lack an understanding of the rationale underlying single-case design $^{2}$ (see note 40, pp. 293-294). Flora (1990) and Dickinson (1989) point out numerous flaws in intrinsic motivation research and provide alternative behav-

\footnotetext{
${ }^{2}$ Sidman (1960) acknowledges that singlecase designs routinely employ small numbers of participants and lack control groups. However, in contrast to between-groups designs, the validity of single-case research is not dependent on large sample size or a control group. Single-case studies derive validity from replication of results across subjects, settings, treatment providers, and so on. Systematic manipulations of independent variables (e.g., exposure to rewards) and the degree of correspondence between those manipulations and behavior change (e.g., length of time spent playing with crayons after being rewarded) provide additional support for the single-case study's validity.
} 
ioral accounts of the data that further lead one to question the generality of Kohn's claims regarding the alleged harm done to children by contingent reward.

In conclusion, a critical evaluation of the intrinsic motivation literature shows substantial disagreement, not so much about the existence of the empirical phenomenon but regarding the meaningfulness and generality of the effect. For example, Cameron and Pierce (1994) found some evidence to suggest that praise may actually be beneficial relative to the neutral (i.e., no harm) findings for tangible, promised "rewards." However, extending these data to recommend that persons avoid the use of tangible rewards in favor of praise in applied settings may be premature. Carton's (1996) recent review suggests that the apparent superiority of praise in facilitating intrinsic interest may derive from a relatively higher frequency and greater immediacy of praise delivery. By comparison, tangible rewards were typically administered only once and sometimes weeks after the promise of reward. Thus, although Bernstein (1990) cautions that behavior-analytic research on intrinsic motivation may not be adequate to dismiss concerns about the long-term impact of the repeated delivery of arbitrary rewards, neither does there appear to be strong evidence for a detrimental effect. Unfortunately, the overall impression given by Kohn's text is that the delivery of contingent reward is a fundamentally flawed, if not morally reprehensible, practice.

\section{Philosophical Differences}

Kohn's conclusions can be challenged by appealing to the empirical literature, yet many of Kohn's statements simply reflect a distaste for what he mistakenly perceives as the fundamental nature of behavioral theory. It is true that behavioral theorists assume that behavior is controlled (or influenced) by its consequences, however difficult to ascertain. Punished by $R e$ - wards reflects a fundamental quarrel, if not contempt, for behaviorism's emphasis on environmental determinism. By contrast, Kohn's constructivist view asserts that individuals may act without regard to the consequences of their behavior, and if unencumbered, will flourish developmentally. Consider the following examples of Kohn's bias toward behavioral interventions, those involving contingent reward in particular:

What concerns me is the practice of using these things as rewards. To take what people want or need and offer it on a contingent basis in order to control how they act-this is where the trouble lies. (p. 4)

A reward by definition, is a desired object or event made conditional on some criterion: only if you do this will you get that. If I promise to give you a banana tomorrow that is not a reward. If I promise to give you a reward tomorrow for helping me out today, that is a reward-and if I don't give it to you, you will probably feel as if you are being punished. To avoid having this happen, I must avoid giving you things on a contingent basis. (p. 53)

Like Kohn, other critics of behaviorism have raised concerns about "bribery" and excessive influence (e.g., B. Schwartz \& Lacey, 1982), yet behaviorists' counterarguments-that rewards are not given for illegal or unethical behavior, that adults themselves are rewarded for work, or that rewards can ultimately be faded (e.g., Malott, Whaley, \& Malott, 1997, pp. 24-25)_-seem to have done little to dull such criticisms. Nevertheless, although Kohn's position and the behavioral position on control and determinism appear to be unreconcilable, perhaps common ground could be reached if Kohn were more familiar with contemporary behavior theory and research (such as the work cited here) in behavior analysis. On the other hand, the views of Kohn and others with apparent strong biases against behaviorism may be difficult to overcome under any circumstances. In either case, the present article shows that behavior analysis has much more to offer than a technology for the arbitrary and heavy- 
handed delivery of selected punishments and reinforcements.

\section{Points of Convergence}

Despite many areas of contention, several points of convergence between Kohn's views and those of behavior analysts can be identified. Many of Kohn's concerns about standard educational practices, such as grading, the classification and labeling of children, and the overreliance on behavioral methods to facilitate control of children's behavior (as opposed to facilitating learning), are consistent with the views of many behavior analysts (e.g., Ferster, 1972; Kazdin, 1989; Michael, 1991; Skinner, 1984). Consistent with Kohn's view that there is more to teaching than grading, behaviorally oriented educational research has provided the details necessary to guide better instructional practices (Kinder \& Carnine, 1991). In fact, Johnson and Layng's (1992) model of behavioral teaching scarcely mentions grading, focusing instead on mastery through better instructional practices. Moreover, Skinner (1984), like Kohn, was an ardent critic of the educational establishment. In a passage that, with few changes, could have been taken directly from Punished by Rewards, Skinner (1984) commented,

\begin{abstract}
But why must we always speak of higher standards for students, merit pay for teachers, and other versions of punitive sanctions? These are the things one thinks of first, and they will no doubt make teachers and students work harder, but they will not necessarily have a better effect. They are more likely to lead to further defection. There is a better way: Give students and teachers better reasons for learning and teaching. That is where behavioral sciences can make a contribution. They can develop instructional practices so effective and attractive in other ways that no one-student, teacher, or administrator-will need to be coerced into using them. (p. 953)
\end{abstract}

It should be noted here that Skinner is not advocating the elimination of contingent reward from the classroom or other environments. Instead, Skinner is arguing that we should build in naturally reinforcing consequences in our instructional design. Reducing the number of errors a child must make before mastering a new concept may make the activity of learning more fun, thus ensuring continued practice. Providing rapid feedback and ample opportunities for the use of new knowledge may facilitate retention and increase the child's access to other sources of reinforcement, such as when a child displays knowledge of the alphabet for proud parents and later learns to write. Although arbitrary rewards such as candy, tokens, and awards can be used to increase the frequency of many socially desirable acts among children, promoting behaviors (perhaps initially aided by the delivery of arbitrary reinforcers) that maximize sources of natural reinforcement is preferable to an exclusive reliance on arbitrary rewards and contrived contingencies (Ferster, 1972). For example, an adult's interest in a child's discussion of a class project and the result of fixing a bicycle can be usefully thought of as "natural" or "automatic" sources of reinforcement for talking and problem solving, respectively (Vaughan \& Michael, 1982).

\section{Conclusion}

The following major criticisms can be made concerning Punished by $R e$ wards. The text entirely ignores a major body of work in contemporary applied behaviorism known as functional analysis. Further, the book selectively ignores the robust successful application of behavior analysis to problems encountered in individual therapy, school consultation, and parenting. In addition, numerous studies in which positive reinforcement has been used to facilitate the acquisition of new behaviors that lead to increased independence and freedom are ignored (e.g., Paul \& Lentz, 1977). It is difficult to conceive how a book that ostensibly seeks to evaluate the role of reward in contemporary American society could ignore so much that is good.

Another glaring omission in Kohn's text is the failure to call for an empir- 
ically based evaluation of his alternatives to behavioral interventions. Effective treatment is both a practical and an ethical issue (Van Houten et al., 1988). That Kohn fails to critically examine his alternative teaching and parenting recommendations suggests that he is more interested in interventions that correspond to his own biases than to empirical data that bear on effective child rearing and educational practices. Fostering effective instructional and child-rearing practices is a task to which all persons in the helping professions should be dedicated.

It should be recognized that Punished by Rewards represents precisely the kind of effort that may be damaging to behavior analysis. The book has the appearance of a scholarly, scientific work, with many, albeit selectively chosen, references to empirical studies and appeals to academic authorities. In addition, the text is easily read and highly quotable (e.g., from the cover of the paperback: "Rewards and punishments are two sides of the same coinand the coin doesn't buy much"). Behavior therapists need to be aware of Kohn's arguments and prepared to discuss qualifications and misrepresentations that are present in Kohn's and other treatments of behaviorism.

One needs only to briefly survey newspapers or television to be bombarded by such sound bites as "children don't learn" or "workers are unproductive and apathetic." Although behaviorism may be a tempting scapegoat for contemporary social problems, Kohn's discussion of behaviorism seems too focused on the mismanagement and misapplication of reinforcement contingencies (including many practices that would probably violate the ethical guidelines for the utilization of behavioral interventions cited above). Nevertheless, Kohn's analysis raises some interesting questions for behavior analysts: To what extent are behavior analysts responsible for the misapplication of behavioral principles? Can behavioral technology be given away if the risk of misapplica- tion is great? Even though the existing data appear to suggest that the risks associated with contingent reward are small, especially when compared to the benefits, data on the extent to which contingency-based behavioral interventions are misapplied remain much needed.

Kohn's portrayal of behavioral science as technological and dehumanizing is not unique (see C. Patterson, 1986). Even prominent behavioral scientists have cautioned that behavior analysis is in danger of becoming a technology of behavior change, as opposed to a highly complex, integrated approach to understanding and modifying behavior (Goldfried, 1995; Goldiamond, 1984; Hayes, Follette, \& Follette, 1995). For example, in an authoritative text on behavior therapy, readers are told, "relative to psychotherapy, behavior therapy concentrates more on behavior itself and less on a presumed underlying cause" (Masters, Burish, Hollon, \& Rimm, 1987, p. 4). Whatever their source, behavior analysts can reduce the likelihood of misconceptions by taking care to present their work in ways that best embody the subtleties and complexities of facilitating lasting behavioral change. Perhaps it is time to begin marketing behavior analysis as the context-dependent study of the causes of behavior and the practical and humane application of that knowledge (e.g., Carr, 1993).

In conclusion, behavior analysis, and interventions derived from this perspective, remain vulnerable to misrepresentation by those who find its precepts unpalatable or objectionable. Such misunderstandings may threaten the future application of this wealth of knowledge about human behavior to efforts to enhance the lives of children. As noted by Schlinger (1995), at this stage in its development, behavior analysis may profit more by favorable mention in the New York Times or on $20 / 20$ than by additional demonstrations of the effectiveness of behavioral technology in the Journal of Applied 
Behavior Analysis. Behavior analysts have good data supporting the efficacy of their interventions, but they must share these data with the public in forums that are familiar to nonscientists (e.g., television, magazines). Interestingly, for a discipline born of the work of a would-be advertising executive, behavior analysts have paid little attention to the need for publicizing the accomplishments of behaviorally oriented scientists and practitioners and defending the practice of behavior analysis (see Chance, 1991, 1992, for rare exceptions). This paper constitutes an effort to clarify an inaccurate depiction of behavior analysis and to contrast that depiction with some of the richness and sophistication of the behavioral perspective. However, in order to respond to misrepresentations, behavior analysts must first contact them. With respect to Punished by Rewards and publications like it, such efforts may be painful, but are necessary to ensure the survival of applied behavioral science.

\section{REFERENCES}

Axelrod, S. (1996). What's wrong with behavior analysis. Journal of Behavioral Education, 6, 247-256.

Azrin, N. H., Stuart, R. B., Risley, T. R., \& Stolz, S. B. (1977). Ethical issues for human services. Behavior Therapy, 8, v-vi.

Balsam, P. D., \& Bondy, A. S. (1983). The negative side effects of reward. Journal of $A p$ plied Behavior Analysis, 16, 283-296.

Bernstein, D. J. (1990). Of carrots and sticks: A review of Deci and Ryan's Intrinsic Motivation and Self-Determination in Human Behavior. Journal of the Experimental Analysis of Behavior, 54, 323-332.

Brigham, T. A. (1989). Managing everyday problems. New York: Guilford.

Buskist, W., Cush, D., \& DeGrandpre, R. J. (1991). The life and times of PSI. Journal of Behavioral Education, 1, 215-234.

Cameron, J., \& Pierce, W. D. (1994). Reinforcement, reward, and intrinsic motivation: A meta-analysis. Review of Educational Research, 64, 363-423.

Carr, E. G. (1993). Behavior analysis is not ultimately about behavior. The Behavior Analyst, 16, 47-50.

Carroll-Rowan, L., \& Miltenberger, R. G. (1994). A comparison of procedures for teaching abduction prevention to preschoolers.
Education and Treatment of Children, 15, 335-354.

Carton, J. S. (1996). The differential effects of tangible rewards and praise on intrinsic motivation: A comparison of cognitive evaluation theory and operant theory. The Behavior Analyst, 19, 237-255.

Chance, P. (1991, June). A gross injustice. Phi Delta Kappan, p. 803.

Chance, P. (1992, November). The rewards of learning. Phi Delta Kappan, pp. 200-207.

Clifford, M. M. (1996). Giant problem with a dwarf solution. Review of Punished by Rewards: The Trouble with Gold Stars, Incentive Plans, A's, Praise, and Other Bribes. Contemporary Psychology, 41, 125-126.

Davidson, G. C., \& Stuart, R. B. (1975). Behavior therapy and civil liberties. American Psychologist, 30, 755-763.

Deci, E. L., \& Ryan, R. M. (1985). Intrinsic motivation and self-determination in human behavior. New York: Plenum.

Dickinson, A. M. (1989). The detrimental effects of extrinsic reinforcement on "intrinsic motivation." The Behavior Analyst, 12, 1-15.

Eisenberger, R., \& Cameron, J. (1996). Detrimental effects of reward: Reality or myth? American Psychologist, 51, 1153-1166.

Elliot, S. N. (1988). Acceptability of behavioral treatments: Review of variables that influence treatment selection. Professional Psychology: Research and Practice, 19, 68-80.

Favell, J. E. (1977). The power of positive reinforcement: A handbook of behavior modifcation. Springfield, IL: Charles C Thomas.

Favell, J. E., \& McGimsey, J. F. (1993). Defining an acceptable treatment environment. In R. Van Houten \& S. Axelrod (Eds.), Behavior analysis and treatment (pp. 25-45). New York: Plenum.

Ferster, C. B. (1965). Classification of behavioral pathology. In L. Krasner \& L. P. Ullmann (Eds.), Research in behavior modification: New developments and implications (pp. 6-26). New York: Holt, Rinehart, \& Winston.

Ferster, C. B. (1972). An experimental analysis of clinical phenomena. The Psychological Record, 22, 1-16.

Flora, S. R. (1990). Undermining intrinsic interest from the standpoint of a behaviorist. The Psychological Record, 40, 323-346.

Gewirtz, J. L. (1978). Social learning in early human development. In A. C. Catania \& T. A. Brigham (Eds.), Handbook of applied behavior analysis: Social and instructional processes (pp. 105-141). New York: Irvington.

Goldfried, M. R. (1995). From cognitive-behavior therapy to psychotherapy integration: An evolving view. New York: Springer.

Goldiamond, I. (1984). Training parent trainers and ethicists in non-linear analysis of behavior. In R. F. Dangel \& R. A. Polster (Eds.), Parent training: Foundations of research and practice (pp. 504-546). New York: Guilford. Goodall, K. (1972, November). Shapers at work. Psychology Today, 53-63, 132-138. 
Hayes, S. C., Follette, W. C., \& Follette, V. M. (1995). Behavior therapy: A contextual approach. In A. S. Gurman \& S. B. Messer (Eds.), Essential psychotherapies: Theory and practice (pp. 128-181). New York: Guilford.

Hayes, S. C., \& Hayes, L. J. (1992). Verbal relations and the evolution of behavior analysis. American Psychologist, 47, 1383-1395.

Huynen, K. B., Lutzker, J. R., Bigelow, K. M., Touchette, P. E., \& Campbell, R. V. (1996). Planned activities training for mothers of children with developmental disabilities: Community generalization and follow-up. Behavior Modification, 20, 406-427.

Johnson, K. R., \& Layng, T. V. J. (1992). Breaking the structuralist barrier: Literacy and numeracy with fluency. American Psychologist, 47, 1475-1490.

Kanfer, F. H., \& Busemeyer, J. R. (1982). The use of problem solving and decision-making in behavior therapy. Clinical Psychology Review, 2, 239-266.

Kazdin, A. E. (1989). Behavior modification in applied settings (4th ed.). Pacific Grove, CA: Brooks/Cole.

Kelley, M. L., \& Stokes, T. F. (1982). Contingency contracting with disadvantaged youths: Improving classroom performance. Journal of Applied Behavior Analysis, 15, 447-454.

Kinder, D., \& Carnine, D. (1991). Direct instruction: What it is and what it is becoming. Journal of Behavioral Education, 1, 193-213.

Kohn, A. (1993). Punished by rewards: The trouble with gold stars, incentive plans, A's. praise, and other bribes. New York: Houghton Mifflin.

Lepper, M. R., \& Greene, D. (1975). Turning play into work: Effects of adult surveillance and extrinsic rewards on children's intrinsic motivation. Journal of Personality and Social Psychology, 31, 479-486.

Lepper, M. R., \& Greene, D. (Eds.). (1978). The hidden costs of reward. New York: Wiley.

Mahoney, M. J. (1995). Cognition and causation in human experience. Journal of Behavior Therapy and Experimental Psychiatry, 26, 275-278.

Malott, R. W., Whaley, D. L., \& Malott, M. E. (1997). Elementary principles of behavior (3rd ed.). Upper Saddle River, NJ: Prentice Hall.

Martin, G. L., \& Hrycaiko, D. (1983). Behavior modification and coaching: Principles, procedures, and research. Springfield, IL: Charles C Thomas.

Masters, J. C., Burish, T. G., Hollon, S. D., \& Rimm, D. C. (1987). Behavior therapy: Techniques and empirical findings (3rd ed.). New York: Harcourt Brace Jovanovich.

Maurice, C. (1996, May). One parent's reflections on persuasion and partnership. Opening address, annual meeting of the Association of Behavior Analysis, San Francisco.

Michael, J. (1991). A behavioral perspective on college teaching. The Behavior Analyst, 14, 229-240.
Miltenberger, R. G. (1997). Behavior modification: Principles and procedures. Pacific Grove, CA: Brooks/Cole.

Montemayor, E. F. (1995). Review of Punished by Rewards: The Trouble with Gold Stars, Incentive Plans, A's, Praise, and Other Bribes. Personnel Psychology, 48, 941-945.

Nevin, A. (1982). Editorial. Journal of the Experimental Analysis of Behavior, 37, 1-4.

Nezu, A. M., \& Nezu, C. M. (Eds.). (1989). Clinical decision making in behavior therapy: A problem solving perspective. Champaign, IL: Research Press.

O'Leary, K. D. (1972). Behavior modification in the classroom: $A$ rejoinder to Winett and Winkler. Journal of Applied Behavior Analysis, 5, 505-515.

Patterson, C. H. (1986). Theories of counseling and psychotherapy (4th ed.). New York: HarperCollins.

Patterson, G. R. (1982). Coercive family process. Eugene, OR: Castalia.

Paul, G. L., \& Lentz, R. J. (1977). Psychosocial treatment of chronic mental patients: Milieu versus social learning programs. Cambridge, MA: Harvard University Press.

Repp, A. C., \& Singh, N. N. (1990). The use of nonaversive and aversive interventions for persons with developmental disabilities. Sycamore, IL: Sycamore.

Schlinger, H. D. (1995, May). Genetic theories of human behavior in the popular press: Should behavior analysts be concerned? In J. Goldschmidt (Chair), Behavior and biology. A symposium presented at the annual meeting of the Association for Behavior Analysis, Washington, DC.

Schwartz, A., \& Goldiamond, I. (1975). Social casework: A behavioral approach. London: Columbia University Press.

Schwartz, B., \& Lacey, H. (1982). Behaviorism, science, \& human nature. New York: Norton.

Scotti, J. R., McMorrow, M. J., \& Trawitzski, A. L. (1993). Behavioral treatment of chronic psychiatric disorders: Publication trends and future directions. Behavior Therapy, 24, 527550.

Sidman, M. (1960). Tactics of scientific research: Evaluating experimental data in psychology. New York: Basic Books.

Sidman, M. (1994). Equivalence relations and behavior: A research story. Boston: Authors Cooperative.

Skinner, B. F. (1953). Science and human behavior. New York: Free Press.

Skinner, B. F. (1966). An operant analysis of problem solving. In B. Kleinmunzt (Ed.), Problem solving: Research, method, and theory (pp. 225-257). New York: Wiley.

Skinner, B. F. (1968). The technology of teaching. New York: Appleton-Century-Crofts.

Skinner, B. F. (1984). The shame of American education. American Psychologist, 39, 947954.

Slavin, R. E. (1991). Cooperative learning and 
group contingencies. Journal of Behavioral Education, 1, 105-115.

Stuart, R. B. (1971). A three-dimensional program for the treatment of obesity. Behavior Research and Therapy, 9, 177-186.

Todd, J. T., \& Morris, E. K. (1983). Misconception and miseducation: Presentations of radical behaviorism in psychology textbooks. The Behavior Analyst, 6, 153-160.

Todd, J. T., \& Morris, E. K. (1992). Case histories in the great power of steady misrepresentation. American Psychologist, 47, 14411453.

Travers, J. F., Elliot, S. N., \& Kratochwill, T. R. (1993). Educational psychology: Effective teaching, effective learning. New York: Brown \& Benchmark.

Turkat, I. D., Harris, F. C., \& Forehand, R. (1979). An assessment of the public reaction to behavior modification. Journal of Behavior Therapy and Experimental Psychiatry, 10, 101-103.

Van Houten, R., Axelrod, S., Bailey, J. S., Favell, J. E., Foxx, R. M., Iwata, B. A., \& Lovaas, O. I. (1988). The right to effective behavioral treatment. The Behavior Analyst, 11, 111114.

Vargas, E. A., \& Vargas, J. S. (1991). Programmed instruction: What it is and how to do it. Journal of Behavioral Education, 1, 235-251.
Vasta, R. (1981). On the rewards and real dangers: A look at the data. Behavior Modification, 5, 129-140.

Vasta, R., \& Stirpe, L. A. (1979). Reinforcement's effects on three measures of children's interest in math. Behavior Modification, 3, 223-244.

Vaughan, M. E., \& Michael, J. L. (1982). Automatic reinforcement: An important but ignored concept. Behaviorism, 10, 217-228.

Vollmer, T. R., \& Northup, J. (1996). Some implications of functional analysis for school psychology. School Psychology Quarterly, 11, 76-92.

West, R. P., \& Young, K. R. (1992). Precision teaching. In R. P. West \& L. A. Hamerlynck (Eds.), Designs for excellence in education: The legacy of B. F. Skinner (pp. 113-146). Longmont, CO: Sopris West.

Winett, R. A., \& Winkler, R. C. (1972). Current behavior modification in the classroom: $\mathrm{Be}$ still, be quiet, be docile. Journal of Applied Behavior Analysis, 5, 499-504.

Wolpe, J. (1978). The humanity of behavior therapy. Journal of Behavior Therapy and Experimental Psychology, 9, 205-209.

Woolfolk, A. E., Woolfolk, R. L., \& Wilson, G. T. (1977). A rose by any other name .... Labeling bias and attitudes toward behavior modification. Journal of Consulting and Clinical Psychology, 45, 184-191. 